20
$\begin{aligned} & \text { On the attack } \\ & \text { congress plans } \\ & \text { deeper probe of } \\ & \begin{array}{l}\text { NIH conflicts } \\ \text { p230 }\end{array}\end{aligned}$

\title{
Iranian physicist locked out of laboratory by energy department
}

Geoff Brumfiel, Washington

His supervisor believes he will be one of the achievers of tomorrow, he has just won an award from the American Physical Society - and he has been banned from his lab for more than a year by the US Department of Energy (DOE).

Shahram Rahatlou is an Iranian highenergy physicist based at the University of California, San Diego (UCSD), whose research involves using the BaBar particle detector at the Stanford Linear Accelerator Center (SLAC). But since February last year, he has been prohibited from entering the grounds of SLAC, where he has worked for the past six years.

Rahatlou declined to comment for this article, but colleagues and laboratory sources told Nature that security officials from the DOE, which oversees SLAC, have offered no explanation for his expulsion and have stated that there will be no appeal.

SLAC is considered to be a civilian facility and does not conduct classified or sensitive research. But security rules have been tightened at such facilities, in part because the DOE is also responsible for research into sensitive topics such as nuclear weapons.

Vivek Sharma, a UCSD physicist and Rahatlou's thesis adviser, says that the 30year-old has not violated any immigration laws, and that his work on BaBar has no bearing on either national security or weapons of mass destruction.

Rahatlou, who is working in the United States on the type of visa - an H-1B - used by many visiting scientists, has continued to work remotely on the BaBar experiment from his office at UCSD. But the ruling effectively puts his career on hold, says Sharma. "If the current isolation remains, then I think he has to leave the field," he says.

Rahatlou's family moved from Iran to Rome in 1987, where he attended the city's 'La Sapienza' university. It was there that he caught the eye of physicist Fernando Ferroni, who believed that Rahatlou showed great promise. "He was very bright," Ferroni recalls. On Ferroni's recommendation, Rahatlou joined Sharma's group in the autumn of 1998. "He's probably the best graduate stu-

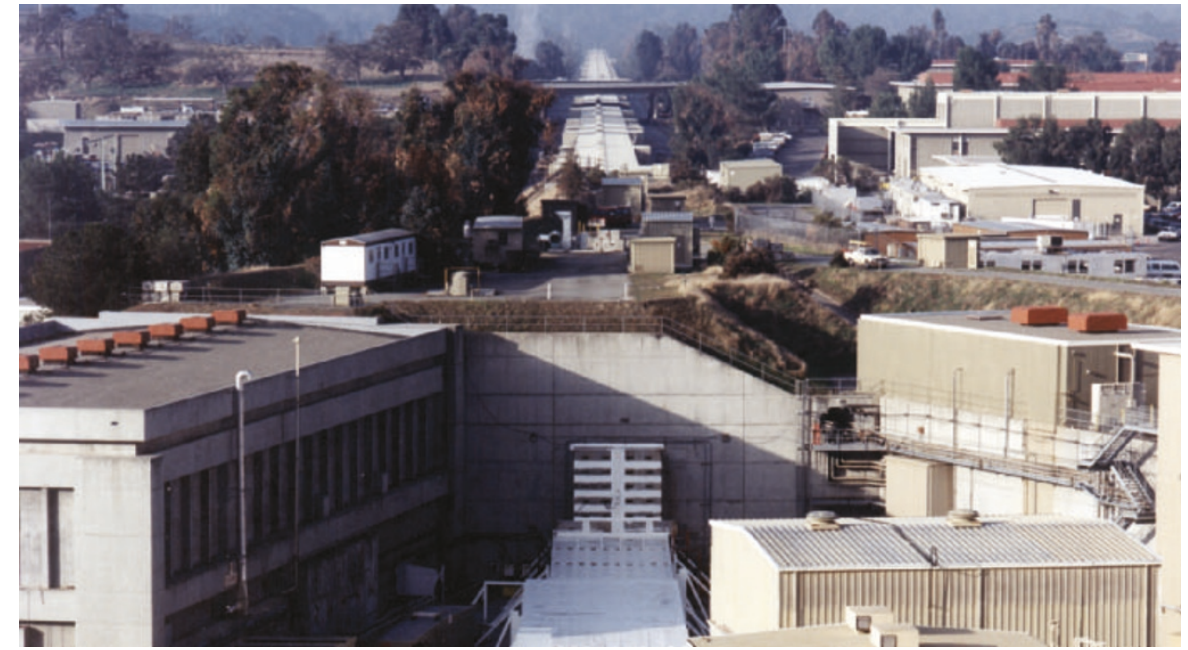

No entry: Shahram Rahatlou (below) has been unable to work at this Stanford lab for more than a year.

dent I have had," Sharma says.

In four years, much of it spent in an office at SLAC, Rahatlou completed his $\mathrm{PhD}$ thesis on how measurements made with BaBar might help to explain why there is vastly more matter than antimatter in the Universe. His work won him the 2004 Mitsuyoshi Tanaka Dissertation Award, an annual prize for an exceptional thesis in experimental particle physics. The award was presented at this month's American Physical Society meeting in Denver.

His troubles began after he completed his $\mathrm{PhD}$ in the autumn of 2002. Rahatlou secured a postdoctoral fellowship at Fermilab near Chicago, Illinois. But to take the position, he had to undergo a background check as part of security procedures introduced after the terrorist attacks of 11 September 2001. Sharma suspects that it was this that led two DOE officials to his UCSD lab in Februarylast year. Sharma says that the officials told him that Rahatlou was no longer welcome at DOE facilities, but that they did not explain why. They also said that the case could not be appealed. Sharma's version of events has been confirmed by several sources in the physics community, who declined to be identified.

A laboratory spokesman says that offi- cials at SLAC, which is run by Stanford University for the DOE, have also not received an explanation for the ruling. "It was a DOE decision," he says.

Other Iranians say that the new security clearances have made it harder for them to work at, or even visit, government facilities. "We were discriminated against even before 11 September," says Niayesh Afshordi, an Iranian graduate student at Princeton University in New Jersey. "But now it has become worse." Afshordi, who expects to complete his $\mathrm{PhD}$ in theoretical astrophysics later this year, says that he had applied for a postdoctoral position at Fermilab, but a fellow researcher there told him that the on-site security clearance would take too long to make it worthwhile.

DOE officials who oversee SLAC failed to return calls enquiring about the decision. Jeanne Lopatto, a spokeswoman at the department's Washington headquarters, said in an email: "DOE will decline to comment on this."

Sharma says he hopes that the DOE will review the ruling. "Rahatlou is the kind of guy who was going on to be the next brilliant faculty at one of the top US universities," he says. "The chances of that happening are dimming day-by-day." 